\title{
PELATIHAN PACKAGING DAN BRANDING SERTA PEMBUKUAN SEDERHANA PADA USAHA YOGHURT DAN ES YOGHURT KECAMATAN KIARA CONDONG
}

\author{
Teguh Iman Basuki \\ teguhib@gmail.com \\ Deddy Rusyandi \\ derusy@gmail.com
}

\section{SEKOLAH TINGGI ILMU EKONOMI EKUITAS}

\begin{abstract}
ABSTRAK
Produk es yoghurt dan yoghurt tidak dapat bertahan lama jika tidak disimpan pada lemari pedingin freezer, tidak adanya merek pada kemasan es yoghurt dan yoghurt menjadikan produk tersebut tidak mudah diingat oleh konsumen serta serta susahnya akses permodalan karena belum memiliki laporan keungan. Kegitan ini bertujuan untuk memberikan pemehaman tentang kewirausahaan, pasar, merek, etika bisnis, teknologi informasi untuk dsain merk dan laporan keuangan. Metode yang digunakan adalah pelatihan serta tutorial kepada para pekerja es yoghurt dan yoghurt. Hasil kegiatan ini peserta memahami pentingnya membuat produk dengan kemasan dan merk yang menarik sehingga memiliki daya jual. Disamping itu mereka mampu merubah mindset untuk menjadi wirausaha dengan memiliki serta memahami pentingnya pembukuan sebagai kontrol keuangan perusahaan juga dapat digunakan untuk persyaratan dalam mengajukan modal kepada lembaga keuanga.
\end{abstract}

Kata Kunci:Packaging, Branding, Pembukuan

\section{PENDAHULUAN}

Potensi produksi es yoghurt dan yoghurtdi Kecamatan Kiara Condong merupakan salah satu potensi lokal yang bisa dikembangkan dengan menciptakan sinergi dengan pasar sehingga kontinuitas produksi bisa dipertahankan dan ditingkatkan sehingga akan menghasilkan pendapatan yang meningkat bagi masyarakat. Industri es yoghurt dan yoghurt yang sudah berlangsung di kelurahan Kebon kangkung masih pada skala industri rumahan (home industri) dengan kapasitas produksi yang sangat terbatas sekitar 7-10 liter/hari dengan harga jual bervariasi, kemasan es es yoghurt dan yoghurt $50 \mathrm{ml}$ dijual dengan harga Rp 2.000,00 per bungkus, kemasan botol ukuran $330 \mathrm{ml} \quad \mathrm{Rp} \quad 10.000,00$ kemasan botol $500 \mathrm{ml}$ Rp 20.000 harga tersebut merupakan harga jual ke konsumen, jika dititp jual kepada pedagang lainnya maka harga tersebut berkurang sekitar $30-40$ persen, sehingga penghasilan kotor per bulan berkisar $\mathrm{Rp}$ $6.000 .000-7.000 .000$ dipotong biaya produksi berkisar 4-4,5 juta rupiah, dengan tenaga kerja 2 orang maka pendapat perorang berkisar 750 ribu - 1,5 juta. Bahan baku produk es yoghurt dan yoghurt ini tidak menggunakan bahan pengawet dan pemanis buatan sehingga dalam suhu alat pendingin refrigerator tidak akan bertahan lebih dari 2 (dua) hari.

Pemasaran produk yang selama ini dilaksanakan, yaitu terbatas dengan titip jual toko-toko kecil yang ada di kantin 
sekolah atau disekitar pemukiman disekitar wilayah kecamatan Kiara Condong, tidak semua toko mau dan bisa dititipkan produk tersebut karena produk tersebut tidak dapat bertahan lama jika tidak disimpan pada lemari pedingin freezer bukan di refrigerator. Serta tidak adanya merek pada kemasan es yoghurt dan yoghurt dan es yoghurt dan yoghurt menjadikan produk tersebut tidak mudah diingat oleh konsumen sehingga harapan konsumen untuk melakukan pembelian berulang menjadi lebih kecil. Terbatasnya kemampuan berwirausaha serta terbatasnya pengetahuan tentang manjemen pemasaran terutama tentangbranding menjadi kendala yang serius dalam mengembangkan wilayah pemasaran sehingga. Disisi lain serta belum mampunya membuat laporan keuangan dapat menyebabkan kurang optimalnya pengembangan potensi produsen es yoghurt dan yoghurt tersebut. Melihat lingkup pasar yang masih terbatas di kecamatan, terdapat potensi pemasaran yang dapat mencakup seluruh kota Bandung untuk bisa dikembangkan.

Kegiatan pengabdian pada masyarakat ini diharapkan agar produsen es yogurt dan yoghurt mampu menjalankan kewirausahaan dengan baik, memahami pasar, membuat satu merek produk yang menarik dan kompetitif, bersaing dengan etis, memgoperasikan computer untuk membuat desain merk dan laporan keuangan.

\section{METODE PELAKSANAAN}

\section{Pendekatan Product - Capacity Up Grading}

Dalam tahap ini bagaimana mereka diberikan pemahaman tentang pentingnya membuat produk dengan kemasan dan merk yang menarik. pendekatan ini dilakukan dengan memberikan teori-teori yang berkaitan dengan pentingnya membuat kemasan dan merk yang mempunyai daya jual sehingga membuat konsumen tertarik untuk membeli. Materimateri yang akan diberikan kepada pemilik usaha es yoghurt dan yoghurt ini adalah bagaimana membuat kemasan yang memenuhi syarat keamanan dan kemanfaatan dimana bisa melindungi produk agar tetap bersih, kemasan yang berkaitan dengan program pemasaran (bagaimana membuat kemasan yang unik, kreatif sehingga berbeda dengan pesaing), dengan membuat kemasan yang unik, yang mempunyai daya tarik visual (warna, bentuk, merek, ilustrasi, huruf dan tata letak) dan daya tarik fungsional (dapat melindungi produk, mudah dibuka atau ditutup kembali untuk disimpan, porsi yang sesuai untuk produk makanan, dapat digunakan kembali (reusable), mudah dibawa, memudahkan pemakai untuk menghabiskannya.

\section{Pendekatan Agen/Subject - Maintenance - Transformasi Agen}

Merubah mindset untuk menjadi wirausaha supaya bisa mempunyai wawasan untuk mengembangkan usaha dengan pelatihan kewirausahaan , pelatihan motivasi, dan pelatihan-pelatihan skill yang menunjang utk progress produktivitasnya, seperti pelatihan pembukuan sederhana dan pelatihan strategi pemasaran.

\section{Organization Approach}

Melakukan pendampingan secara intensif dengan mengadvokasi kelompok usaha terhadap akses-akses informasi yang mendukung keberhasilan usaha seperti KUR, Perbankan dan lain-lain.

\section{Metode Tutorial Pembukuan}

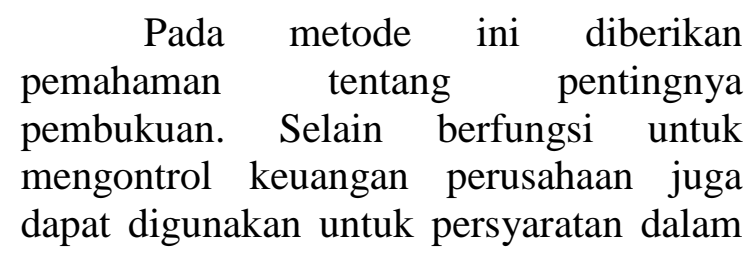


mengajukan modal kepada lembaga keuangan. Selanjutnya mitra diberikan pelatihan dan tutorial bagaimana menggunakan program aplikasi dengan menggunakan software Microsoft Excel, mulai dari entri jurnal umum, neraca saldo sampai menghasilkan laporan keuangan.

\section{HASIL DAN LUARAN}

Berdasarkan pemaparan materi dan diskusi dengan para peserta pelatihan selama proses kegiatan berlangsung, kegiatan pengabdian pada masyarakat ini memperoleh hasil sebagai berikut:

\section{Hasil Pelatihan}

1. Mitra sebagai pesertamemahami pentingnya membuat produk dengan kemasan dan merk yang menarik.

2. Mitra sebagai pesertamemahami pentingnya membuat kemasan dan merk yang mempunyai daya jual sehingga membuat konsumen tertarik untuk membeli.

3. Mitra sebagai pesertamampu membuat kemasan yang memenuhi syarat keamanan dan kemanfaatan dimana bisa melindungi produk agar tetap bersih.

4. Mitra sebagai pesertamampuberkreasi membuat kemasan yang unik, kreatif sehingga berbeda dengan pesaing. mempunyai daya tarik visual dari segi warna, bentuk, merk, ilustrasi, huruf dan tata letak.

5. Mitra sebagai pesertamampumemahami bagaimana membangun merk yang kreatif yang dimana menimbulkan rasa penasaran konsumen untuk membeli.

6. Mitra sebagai pesertasedikit demi sedikit mampumerubah mindset untuk menjadi wirausahadenganmemiliki.

7. Mitra sebagai pesertamampumemahami bagaimana suatu merk yang dikaitkan dengan benefit sehingga konsumen langsung dapat mengetahui manfaat apa yang dirasakan setelah menggunakan produk tersebut.

8. Mitra sebagai pesertasedikit demi sedikitmemahami pentingnya pembukuan sebagai kontrol keuangan perusahaan juga dapat digunakan untuk persyaratan dalam mengajukan modal kepada lembaga keuangan.

9. Mitra sebagai pesertasedikit demi sedikit memahami bagaimana menggunakan program aplikasi dengan menggunakan softwareMicrosoft Excel, mulai dari entri jurnal umum, neraca saldo sampai menghasilkan laporan keuangan.

\section{Luaran}

Luaran kegiatan Pengabdian Pada Masyarakat produsen es yoghurt and yoghurt di Kecamatan Kiara Condong adalah sebagai berikut:

1. Modul pelatihan packaging dan merk.

2. Modul tutorial membuat laporan keuangan dengan Ms Excel.

3. Aplikasi laporan keuangan dengan Software Ms Excel.

\section{KESIMPULAN}

Produsen es yoghurt dan yoghurt di kecamatan Kiara Condong dalam melakukan usahanya masih dijalankan secara alamiah dan mengandalkan naluri berdagang yang mereka miliki, namun melalui pelatihan yang diberikan terdapat perkembangan pemahaman dari mereka terhadap pentingnya kemasan dan merk serta pembukan. Namun demikian pemahaman terhadap materti yang diberikan masih relatif lambat.

\section{DAFTAR PUSTAKA}

Agustina, W. (2010). Pengemasan, Desain dan Pelabelan Produk Makanan. Subang: LIPI. 
Bandung, B. P. (2015). Statistik Daerah Tahun 2015 Kecamatan Kiara Condong. Bandung: Badan Pusat Statistik Kota Bandung.

Diknas, D. P. (2010). Manajemen Usaha Kecil. Jakarta: Direktorat Pembinan Kursus dan Kelembagaan Ditjen Pendidikan Formal dan Nonformal Diknas.
Knapp, D. E. (2002). The Brand Mindset. Yogyakarta: ANDI Yogyakarta.

Terence, S. (2006). Marketing \& Promotion. London: routledge. 